\title{
Layer Growth in Co(W)-Zn Systems at Hard Metal Recycling
}

\author{
NADINE KOERBLER, ${ }^{1,5}$ TAMARA EBNER,${ }^{1}$ STEFAN LUIDOLD,${ }^{1}$ \\ HELMUT ANTREKOWITSCH ${ }^{2}$ CHRISTOPH CZETTL, ${ }^{3}$ \\ CHRISTIAN STORF,${ }^{3}$ AMY CLARKE,${ }^{4}$ and KESTER CLARKE ${ }^{4}$
}

\begin{abstract}
1.-CD-Laboratory for Extractive Metallurgy of Technological Metals, Nonferrous Metallurgy, Montanuniversitaet Leoben, Franz-Josef-St. 18, 8700 Leoben, Austria. 2.-Chair of Nonferrousmetallurgy, Montanuniversitaet Leoben, Franz-Josef-St. 18, 8700 Leoben, Austria. 3.-Ceratizit, Metallwerk-Plansee-Straße 71, 6600 Breitenwang, Austria. 4.-Metallurgical and Materials Engineering, Colorado School of Mines, 1500 Illinois St., Golden, CO, USA. 5.-e-mail: nadine.koerbler@unileoben.ac.at
\end{abstract}

The influence of $\mathrm{W}$ content on the $\mathrm{Co}(\mathrm{W}) \mathrm{Zn}$ system and the behavior of individual elements was investigated. Cobalt is a so-called critical element and is one of the main parts in hard metal products. Because of its toxicity, it requires special care in handling. Further optimization of hard metal recycling, especially by the zinc process, is needed to use scrap as a secondary resource. In this work, $\mathrm{Co}(\mathrm{W})$ materials were put in contact with liquid zinc and held at specific temperatures, giving insight into the formation of intermetallic $\mathrm{Co}-\mathrm{Zn}$ phases by varying the temperature, duration, and $\mathrm{W}$ content. Lower temperatures led to a minimum layer width, and increasing temperatures and $\mathrm{W}$ contents resulted in greater thicknesses of the intermetallic phases. The element distribution analyses show that $\mathrm{W}$ diffuses from the base material through the intermetallic Co-Zn layer and accumulates at detached Co-Zn phases, forming thin, enriched filaments. This can be attributed to the fact that the intermetallic $\mathrm{Co}-\mathrm{Zn}$ phases and $\mathrm{Zn}$ have no solubility in W. Consequently, the latter is located on the outside of these phases. The combination of practical experiments and statistical analyses will ultimately provide a possibility for improving recycling processes.

\section{INTRODUCTION}

The increasing demand for critical materials and elements affects ecologic and social consequences, so the use of scrap as a source of raw materials is timely and important. It is essential to act carefully and apply environmentally friendly and resourceefficient methods, especially in handling and processing critical metals. This enables conservation of primary resources to ensure constant raw material flow. Because of the toxicity of some critical elements, special care is required to maintain a healthy environment. Frequently, these elements are mined in politically unstable countries, with little to no environmental standards. Therefore, the aim is to use different recycling methods to recover critical elements from scrap to protect natural resources and to minimize the dependence on the raw material supply by other countries. ${ }^{1,2}$
Critical metals include cobalt and tungsten, which are the main constituents in the powder metallurgical production of hard metals. Co is used as a tough binder, and $\mathrm{W}$ serves in the form of tungsten carbide (WC) as the hard phase. During the production of various hard metal products, such as cutting tools, a compaction of the metal powder by liquid-phase sintering at high temperatures takes place. In this case, some $\mathrm{W}$ is dissolved in Co, which does not completely precipitate at lower temperatures, so $\mathrm{W}$ remains in the binder phase. This can negatively influence the recycling of hard metals. For hard metal recycling, different methods are applied: the indirect, semi-direct, and direct routes. The direct processes are the most environmentally friendly and include the zinc process, in which solid hard metal scrap is placed in contact with liquid zinc. ${ }^{3,4}$ Figure 1 illustrates the schema of the zinc process. 


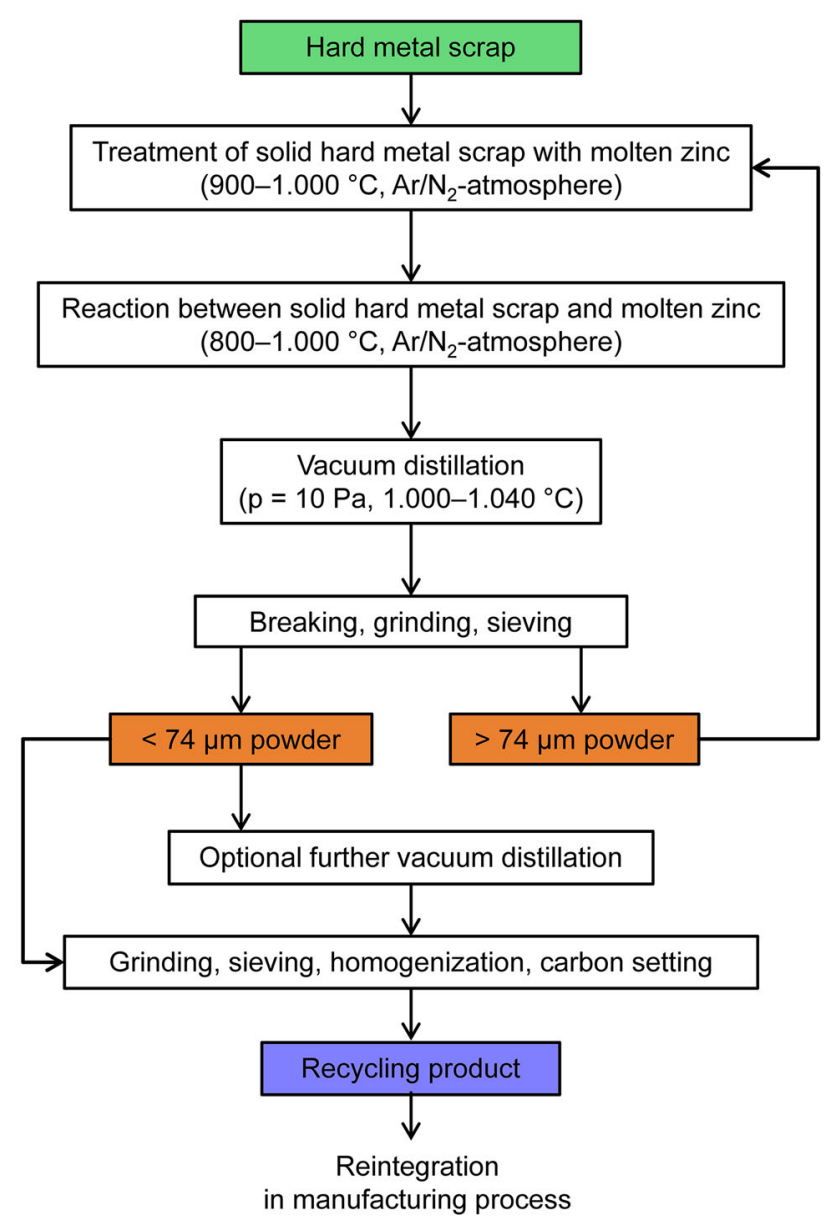

Fig. 1. Flow sheet of hard metal recycling applying the zinc process. Adapted from Ref. 5.

Co and $\mathrm{Zn}$ react at the interface, where intermetallic $\mathrm{Co}-\mathrm{Zn}$ phases are formed. As a result of increasing amounts of $\mathrm{Co}-\mathrm{Zn}$ phases relative to $\mathrm{Co}$, the WC-Co separates, with the WC detaching in a lamellar manner into the liquid zinc. A subsequent vacuum distillation removes the zinc, and a porous sponge of solid WC and Co remains. After a special treatment and some compensation of losses, this material can be reintegrated into the manufacturing process. ${ }^{4,6-10}$

Investigations of the zinc process are commonly performed by using a range of simplified laboratoryscale experiments. The current tests combine practical measurements at a small scale, with theoretical statistical analyses. Such experiments are necessary for further improvements and optimization of already existing recycling processes. The focus of this study is the evaluation of the influence of $\mathrm{W}$ on the formed intermetallic phases and the behavior of the $\mathrm{Co}(\mathrm{W})$ system in a $\mathrm{Zn}$ matrix. Therefore, liquid $\mathrm{Zn}$ was cast onto solid $\mathrm{Co}(\mathrm{W})$ cubes in crucibles, which were kept at defined temperatures $\left(600^{\circ} \mathrm{C}, 675^{\circ} \mathrm{C}, 750^{\circ} \mathrm{C}\right)$ and durations $(0.5 \mathrm{~h}$, $4.25 \mathrm{~h}, 8 \mathrm{~h})$ in a nitrogen atmosphere furnace.
Further microstructural examinations included scanning electron microscopy (SEM) and thickness measurements by light optical microscopy (LOM).

\section{MATERIALS AND METHODS}

\section{Design of Experiments}

The design of experiments, which was compiled by the statistical software MODDE 12 , included 27 experiments that varied parameter durations, including the temperature and desired $\mathrm{W}$ content of the base material with associated layer thicknesses and four investigations (14-1 to 14-4) with the same conditions to check the representativeness of the tests (seen Table I).

\section{Materials}

The applied recycling method depends upon the reaction between Co and $\mathrm{Zn}$, along with the impact of several alloying elements, especially tungsten. To investigate the influence of tungsten on the reaction between $\mathrm{Co}$ and $\mathrm{Zn}$ alloys of $\mathrm{Co}(\mathrm{W})$, nominal $\mathrm{W}$ contents of 0 wt. $\%, 5$ wt. $\%$, and 10 wt.\% were considered. After the processing, the measured $\mathrm{W}$ contents (SEM) were $0 \mathrm{wt} . \%$, $3.77 \mathrm{wt} . \%$, and $4.01 \mathrm{wt} \%$. The powders used were melted in an induction furnace at a temperature of $1530^{\circ} \mathrm{C}$, with a holding duration of $3 \mathrm{~h}$. Then, the solidified and compacted material was sliced into cubes with an edge length of $1 \mathrm{~cm}$, which were positioned in a quartz crucible. The crucibles were filled with liquid $99.999 \%$ pure zinc (SEM) and held in a nitrogen atmosphere furnace at defined temperatures $\left(600^{\circ} \mathrm{C}, 675^{\circ} \mathrm{C}\right.$, or $\left.750^{\circ} \mathrm{C}\right)$ and holding durations $(0.5 \mathrm{~h}, 4.25 \mathrm{~h}$, or $8 \mathrm{~h})$. The solid $\mathrm{Co}(\mathrm{W})$ interacted with the liquid zinc and formed intermetallic Co-Zn phases. After holding for specified times, the $\mathrm{Co}(\mathrm{W})-\mathrm{Zn}$ samples were air-cooled and machined. The designation of each sample, for example, $6754.255 \mathrm{~W}$, contains the temperature $\left(600^{\circ} \mathrm{C}, 675^{\circ} \mathrm{C}\right.$, or $\left.750^{\circ} \mathrm{C}\right)$, holding duration $(0.5 \mathrm{~h}$, $4.25 \mathrm{~h}$, or $8 \mathrm{~h})$, and desired $\mathrm{W}$ content $(0 \mathrm{wt} . \%$, 5 wt.\%, or 10 wt.\%).

\section{Sample Preparation and Analysis}

A smooth sample surface resulted from metallurgical preparation in water. The polishing utilized a diamond suspension $(1 \mu \mathrm{m})$ followed by Eposal micro-etching.

Figure 2 shows an example of the received samples, including the $\mathrm{Co}(\mathrm{W})$ cubes. The area around the cubes shows the intermetallic Co-Zn phases formed, surrounded by zinc.

The microstructure of the $\mathrm{Co}(\mathrm{W})-\mathrm{Zn}$ surface was analyzed by an SEM (JEOL JSM IT-300 LV) equipped with an EDS analyzer. The layer thicknesses of the intermetallic phases were measured with a light optical microscope. 
Table I. Design of experiments, including sample designation, temperature, holding duration, W contents of the base material, and associated average layer thicknesses (measured by light optical microscopy)

\begin{tabular}{|c|c|c|c|c|c|}
\hline $\begin{array}{l}\text { Sample } \\
\text { designation }\end{array}$ & $\begin{array}{c}\text { Temperature } \\
\left({ }^{\circ} \mathbf{C}\right)\end{array}$ & $\underset{(\%)}{\text { Target value }}$ & $\underset{(\%)}{\text { Actual value }}$ & $\begin{array}{c}\text { Duration } \\
\text { (h) }\end{array}$ & $\begin{array}{c}\text { Layer thickness } \\
\qquad(\mu \mathrm{m})\end{array}$ \\
\hline 1 & 600 & 0 & 0 & 0.5 & 56.0 \\
\hline 2 & 675 & 0 & 0 & 0.5 & 69.0 \\
\hline 3 & 750 & 0 & 0 & 0.5 & 93.0 \\
\hline 4 & 600 & 0 & 0 & 4.25 & 207 \\
\hline 5 & 675 & 0 & 0 & 4.25 & 154 \\
\hline 6 & 750 & 0 & 0 & 4.25 & 97.0 \\
\hline 7 & 600 & 0 & 0 & 8 & 212 \\
\hline 8 & 675 & 0 & 0 & 8 & 133 \\
\hline 9 & 750 & 0 & 0 & 8 & 94.0 \\
\hline 10 & 600 & 5 & 3.77 & 0.5 & 43.0 \\
\hline 11 & 675 & 5 & 3.77 & 0.5 & 85.0 \\
\hline 12 & 750 & 5 & 3.77 & 0.5 & 96.0 \\
\hline 13 & 600 & 5 & 3.77 & 4.25 & 54.0 \\
\hline $14-1$ & 675 & 5 & 3.77 & 4.25 & 112 \\
\hline 15 & 750 & 5 & 3.77 & 4.25 & 45.0 \\
\hline 16 & 600 & 5 & 3.77 & 8 & 190 \\
\hline 17 & 675 & 5 & 3.77 & 8 & 121 \\
\hline 18 & 750 & 5 & 3.77 & 8 & 47.0 \\
\hline 19 & 600 & 10 & 4.01 & 0.5 & 63.0 \\
\hline 20 & 675 & 10 & 4.01 & 0.5 & 65.0 \\
\hline 21 & 750 & 10 & 4.01 & 0.5 & 115 \\
\hline 22 & 600 & 10 & 4.01 & 4.25 & 76.0 \\
\hline 23 & 675 & 10 & 4.01 & 4.25 & 130 \\
\hline 24 & 750 & 10 & 4.01 & 4.25 & 105 \\
\hline 25 & 600 & 10 & 4.01 & 8 & 101 \\
\hline 26 & 675 & 10 & 4.01 & 8 & 112 \\
\hline 27 & 750 & 10 & 4.01 & 8 & 180 \\
\hline $14-2$ & 675 & 5 & 3.77 & 4.25 & 211 \\
\hline $14-3$ & 675 & 5 & 3.77 & 4.25 & 192 \\
\hline $14-4$ & 675 & 5 & 3.77 & 4.25 & 213 \\
\hline
\end{tabular}

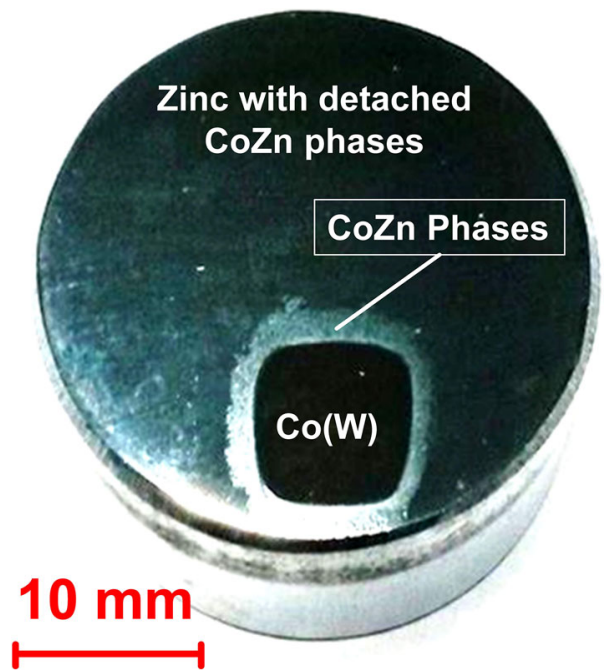

Fig. 2. Zinc casting sample containing the $\mathrm{Co}(\mathrm{W})$ cube with intermetallic Co-Zn phases around the cube.

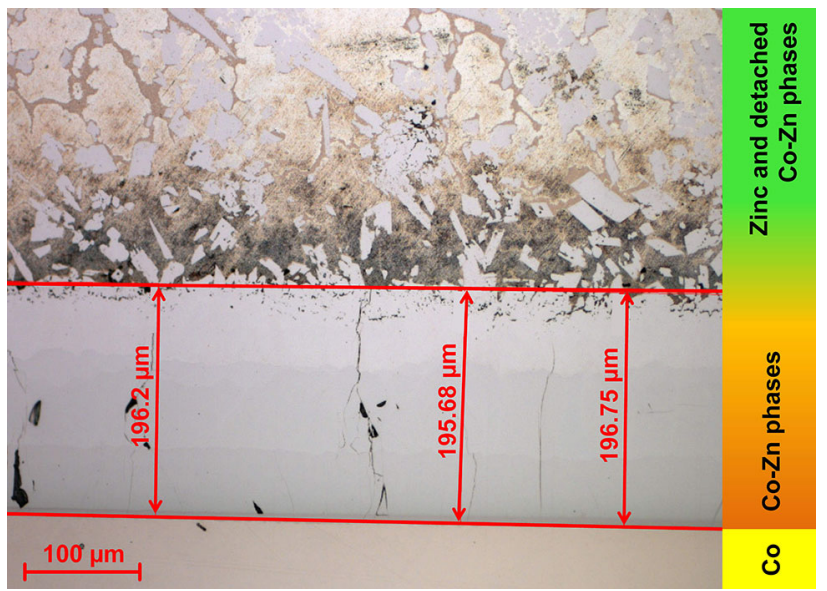

Fig. 3. Layer thickness measurements of an etched sample 17 (675 $85 \mathrm{~W}$ ) with $\mathrm{Co}(\mathrm{W})$ material, intermetallic layer, and liquid zinc detached intermetallic phases (light optical image). 


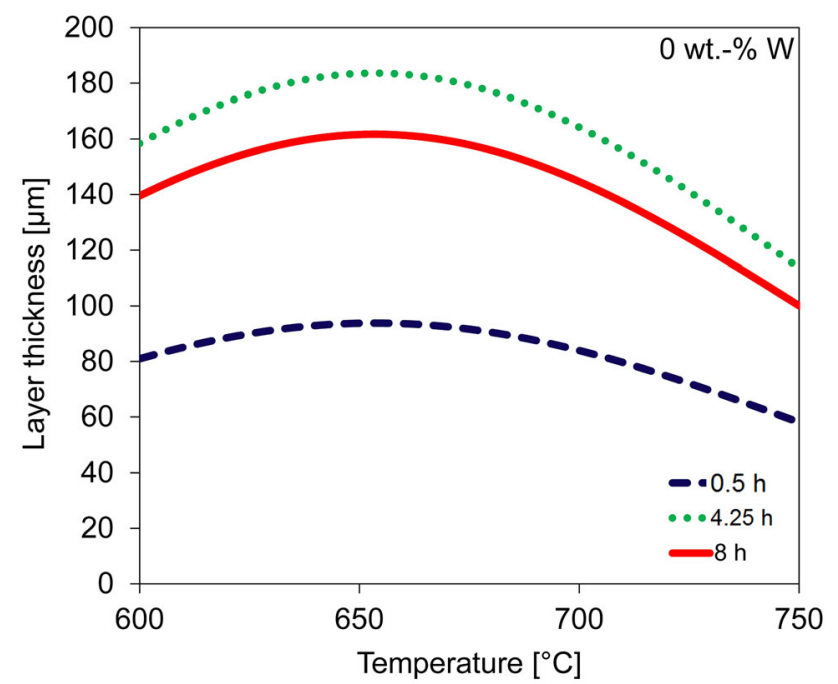

Fig. 4. MODDE evaluation of the layer thicknesses at $0 \mathrm{wt} \% \mathrm{~W}$, depending on duration and temperature.

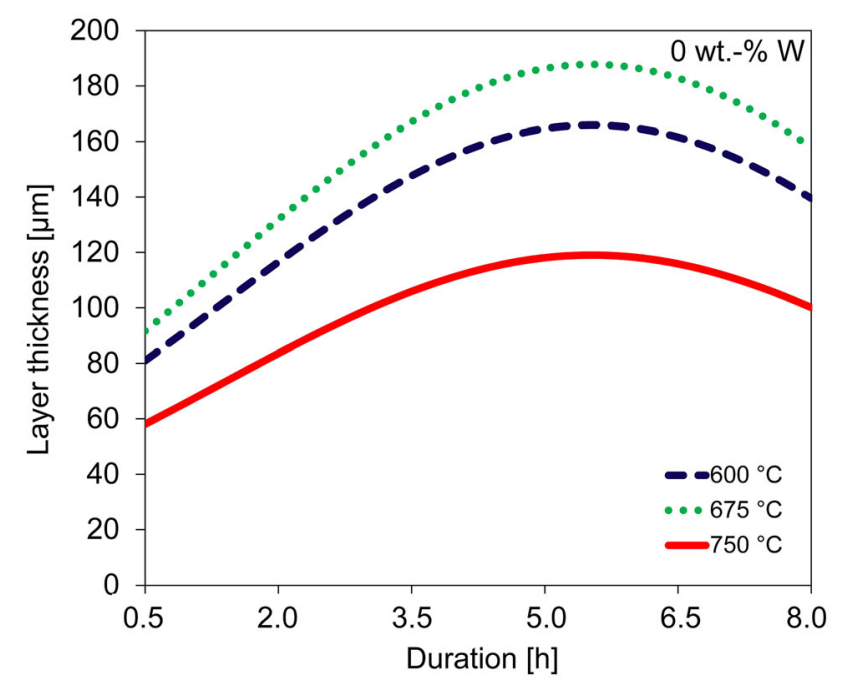

Fig. 5. MODDE evaluation of layer thicknesses at $0 \mathrm{wt} . \% \mathrm{~W}$, depending on duration and temperature.

\section{LOM Layer Thickness Measurements}

The statistical analysis of the total thickness of the intermetallic Co-Zn phases formed at the interface between $\mathrm{Co}(\mathrm{W})$ and $\mathrm{Zn}$ with MODDE 12 constitutes the main part of this research. The parameters used ranged from $0 \mathrm{wt} \% \mathrm{~W}$ to $10 \mathrm{wt} . \% \mathrm{~W}$ and $0.5-8 \mathrm{~h}$ of holding time at the temperatures $600-750^{\circ} \mathrm{C}$. Temperature, duration, and $\mathrm{W}$ content were found to influence the thicknesses of the intermetallic Co-Zn layers, which were measured in a light optical microscope. Figure 3 demonstrates the measurement process on sample $17(67585 \mathrm{~W})$.

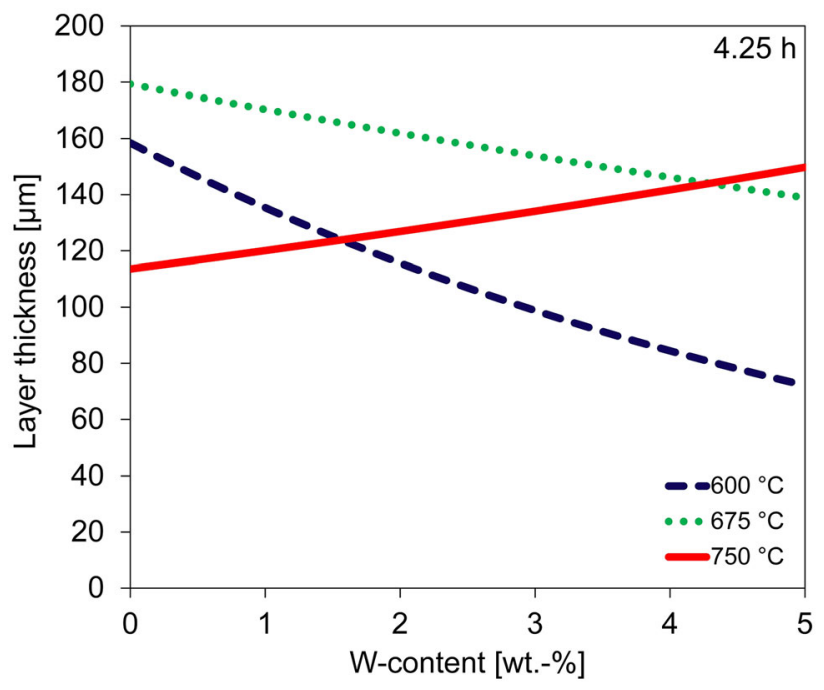

Fig. 6. MODDE evaluation of the layer thicknesses at $4.25 \mathrm{~h}$, depending on the $\mathrm{W}$ content and temperature.

A list of the average layer thicknesses with the associated temperature, treatment duration, and $\mathrm{W}$ content is provided in Table I.

The statistical program MODDE 12 PRO served for the calculation of diagrams with different temperatures, holding durations, and W contents. Figure 4 shows the evolution of layer thickness with temperatures from $600^{\circ} \mathrm{C}$ to $750^{\circ} \mathrm{C}$ for $0 \mathrm{wt} . \% \mathrm{~W}$. The highest layer thickness of approximately $175 \mu \mathrm{m}$ appears at the temperature $650^{\circ} \mathrm{C}$. Increasing temperature has a negative effect and leads to thinner layers.

Figure 5 shows the formation of intermetallic phases at treatment durations ranging from $0.5 \mathrm{~h}$ to $8 \mathrm{~h}$ at a W content of $0 \mathrm{wt} . \%$. At a reaction duration of $5.5 \mathrm{~h}$, a maximum of approximately $160 \mu \mathrm{m}$ occurs. Shorter treatment durations result in smaller layer thicknesses as well as durations $>6.5 \mathrm{~h}$.

Figure 6 highlights the influence of the $\mathrm{W}$ content ranging from $0 \mathrm{wt} . \% \mathrm{~W}$ to $5 \mathrm{wt} . \% \mathrm{~W}$ for a treatment duration of $4.25 \mathrm{~h}$. Low temperatures of $600^{\circ} \mathrm{C}$ and $650^{\circ} \mathrm{C}$ show a negative effect on the layer growth. The higher temperature of $750^{\circ} \mathrm{C}$ results in a maximum thickness of approximately $150 \mu \mathrm{m}$ for 5 wt.\% of W. Decreasing $\mathrm{W}$ content results in thinner intermetallic layers at $750^{\circ} \mathrm{C}$.

\section{SEM Analysis}

The distribution of different elements such as tungsten, cobalt, and zinc in the $\mathrm{Co}(\mathrm{W}) \mathrm{Zn}$ system was analyzed by an SEM via EDS. Figure 7 shows the location of tungsten (A), cobalt (B), and zinc (C) in sample 14-1 (675 4.25 5 W). The colors in these figures indicate the concentration of the elements. $\mathrm{W}$ is homogeneously distributed in the base 

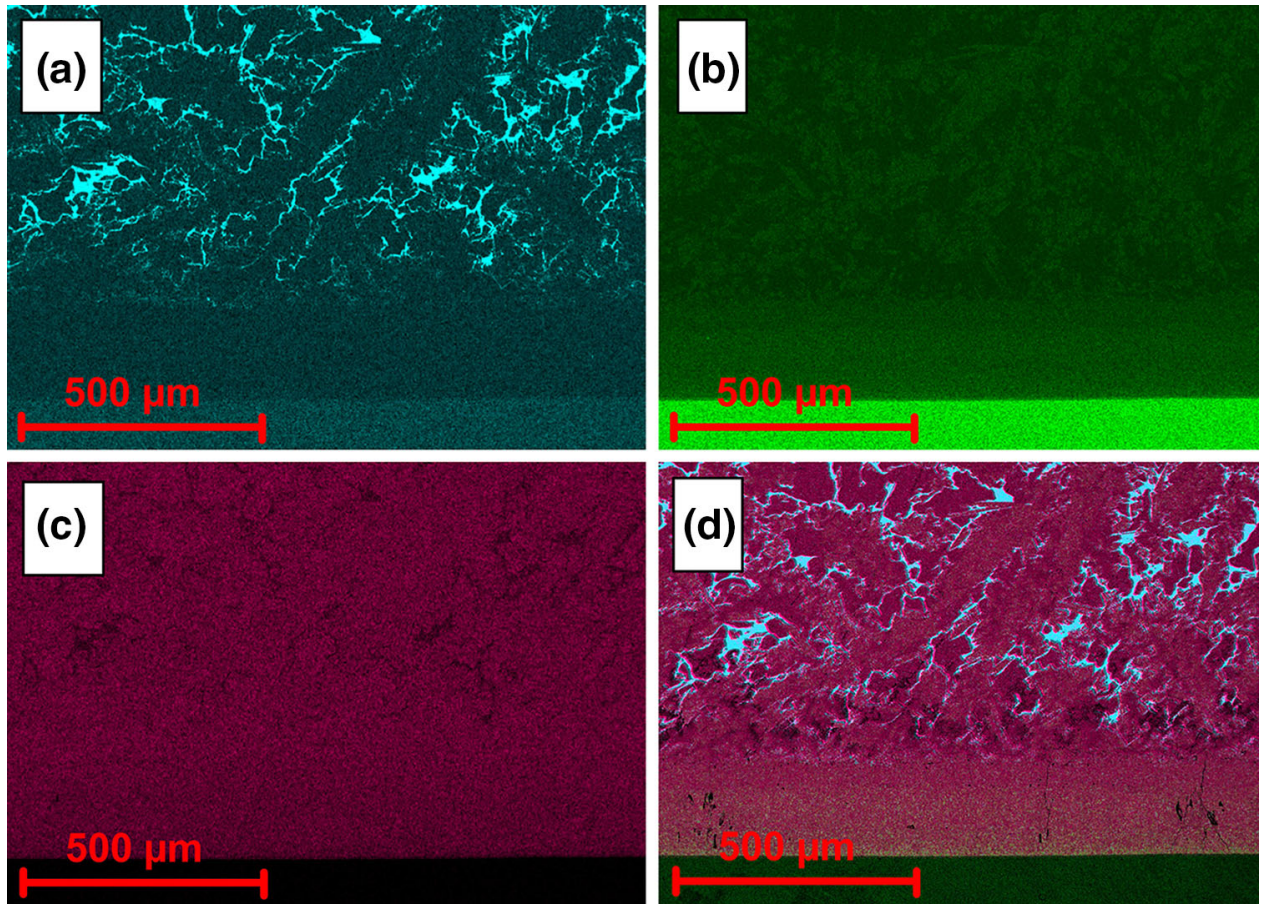

Fig. 7. Element distribution of (A) tungsten, (B) cobalt, and (C) zinc in sample 14-1 (675 4.25 $5 \mathrm{~W}$ ) and (D) a summary of all of the elements (EDS).

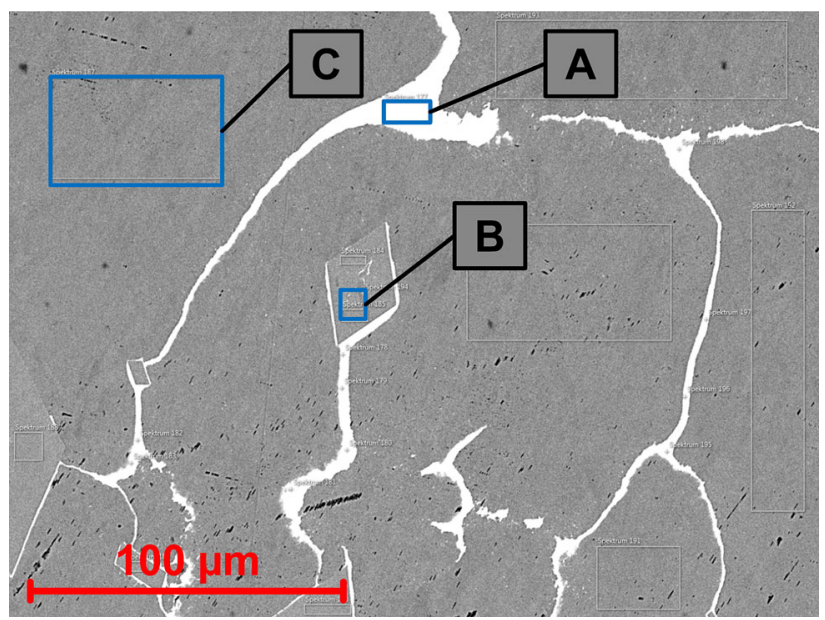

Fig. 8. SEM/EDS mapping of the outer area representing zinc, detached Co-Zn phases, and W enrichments in sample 13 (600 4.25 $5 \mathrm{~W})$; analyzed areas: (A) W-rich regions; (B) intermetallic Co-Zn phases; (C) pure zinc.

material and hardly exists in the intermetallic layer. Accumulations of $\mathrm{W}$ appear in the outer layer. Comparison of $\mathrm{Co}$ and $\mathrm{Zn}$ illustrates a transition of the $\mathrm{Co}(\mathrm{W})$ material via the intermetallic Co-Zn phases to the area where $\mathrm{Zn}$ dominates. Some regions show higher contents of $\mathrm{Co}$ and $\mathrm{Zn}$, which represent the previously mentioned detached intermetallic Co-Zn phases. Figure 7 (D) presents a summary of all of the elements measured with EDS.

Figure 8 depicts accumulations of tungsten around the intermetallic $\mathrm{Co}-\mathrm{Zn}$ phases in sample $13(6004.255 \mathrm{~W})$ analyzed by SEM/EDS.
The bright areas are enrichments of tungsten between intermetallic $\mathrm{Co}-\mathrm{Zn}$ phases. The results from three selected spectra include the liquid zinc phase, an intermetallic phase, and a W-rich phase. The bright regions (A) consist of approximately $53 \%$ $\mathrm{W}$ and $47 \% \mathrm{Zn}$. The angular phases are $98.9 \%$ zinc with $1.1 \%$ cobalt $(\mathrm{B})$. The gray regions $(\mathrm{C})$ correspond to $100 \%$ zinc.

\section{RESULTS AND DISCUSSION}

The results of the layer thickness measurements, shown in Figs. 4, 5 and 6, illustrate the influence of the investigated parameters. At varying temperatures (Fig. 4), a maximum appears at medium temperatures of $675^{\circ} \mathrm{C}$, duration of $4.25 \mathrm{~h}$, and $\mathrm{W}$ content of $0 \mathrm{wt} . \%$. At higher values of $750^{\circ} \mathrm{C}$, a negative effect occurs because WC detachment proceeds faster than the formation of $\mathrm{Co}-\mathrm{Zn}$ phases. $\mathrm{A}$ rising $\mathrm{W}$ content shifts the maximum thicknesses to higher temperatures. Low temperatures lead to thinner layers.

The same is shown in Fig. 5, where increasing treatment durations lead to lower layer thicknesses, caused by the dominant detachment of intermetallic phases. A maximum occurs at medium durations of $5.5 \mathrm{~h}$, medium temperature of $675^{\circ} \mathrm{C}$, and $\mathrm{W}$ content of 0 wt.\%.

Figure 6 includes varying $\mathrm{W}$ contents and demonstrates that low concentrations have negative effects on the layer growth. It is seen that low and medium temperatures obtain a trend to decreasing layer thicknesses with increasing $\mathrm{W}$ contents. The 
highest temperature of $750^{\circ} \mathrm{C}$ and $\mathrm{W}$ content of $5 \mathrm{wt} . \%$ resulted in a maximum of intermetallic layer thicknesses at medium holding durations of $4.25 \mathrm{~h}$.

The chemical SEM/EDS mapping (Fig. 7) illustrates the distribution of the individual elements such as Co, W, and Zn. W is only detectable in the base material and in the area around the detached intermetallic Co-Zn phases, but not in the Co-Zn phases. Because of the insolubility of $\mathrm{W}$ in $\mathrm{Zn}$, it is displaced to the outer regions and forms enrichments at already detached intermetallic phases.

Figure 8 shows a sample with 5 wt. $\% \mathrm{~W}$, which was treated at $600^{\circ} \mathrm{C}$ with a duration of $4.25 \mathrm{~h}$. The spots A, B, and C were measured with an SEM/EDS. It is seen that there are compact $\mathrm{W}$ enrichments to a concentration of $53 \% \mathrm{~W}$ enclosing $\mathrm{Co}-\mathrm{Zn}$ phases (A), which are surrounded by pure $\mathrm{Zn}(\mathrm{C})$. The intermetallic phases consist of approximately $98 \% \mathrm{Zn}$ and $2 \%$ Co (B). Due to naturally occurring convections in the liquid zinc, caused by temperature gradients in the melt and crucibles, solid W agglomerates to visible enrichments.

\section{CONCLUSION}

For the optimization of individual recycling processes of critical metals such as Co and W for hard metal commodities, an understanding of the influence of $\mathrm{W}$ content on layer growth in the $\mathrm{Co}(\mathrm{W}) \mathrm{Zn}$ system is essential. Temperature, duration, and $\mathrm{W}$ content were examined to determine the effects on layer thickness. Combined investigation concepts, measuring layer thicknesses with distribution analyses, were applied.

To recycle hard metal, several methods are applied, including indirect, semi-direct, and direct processes. A direct method, the zinc process, represents the most environmentally friendly process. In this method, solid hard metal scrap is put in contact with liquid zinc. Reaction between Co and $\mathrm{Zn}$ forms Co-Zn phases. Because of the increasing volume, the connection between Co and WC breaks. A subsequent vacuum distillation removes the zinc and a porous sponge of WC and Co remains, which can be reintegrated into the manufacturing process.

To better understand and optimize the existing zinc process, further investigations concerning the behavior of $\mathrm{W}$ in the first stage of the zinc process are needed. For simplicity, $\mathrm{Co}(\mathrm{W})$ served as the base material, which contacted the liquid zinc. By varying the parameters duration, temperature, and $\mathrm{W}$ content, the formation of the intermetallic Co- $\mathrm{Zn}$ phases was analyzed (LOM).

The results indicated that a maximum total layer thickness occurs at medium durations for varying temperatures. In addition, the results of a variable duration show that a maximum can be achieved at medium temperatures and low $\mathrm{W}$ contents. With increasing $\mathrm{W}$ concentration, the maximum shifts to higher temperatures. By varying the $\mathrm{W}$ content, it can be seen that a maximum appears at medium holding durations and high temperatures.

Chemical mapping, which was done by SEM/EDS, illustrates the location of the individual elements such as tungsten, cobalt, and zinc after the experiments. The results show that $\mathrm{W}$ diffuses through the intermetallic Co-Zn layer and accumulates at the surface of the already detached intermetallic Co-Zn phases.

Finally, the results of this study lead to the conclusion that pure $\mathrm{W}$ enrichments will be present in practice after a vacuum distillation of zinc next to the porous WC and Co. Accumulations lead to W losses in WC, which is necessary for hard metal production, and have a negative influence on recycling processes and the quality of secondary resources.

By combining the results of the layer thickness measurements and element distributions, the microstructural evolution during the zinc process was investigated to develop improvements. Future experiments will deal with the decomposition of hard metals to gain further optimization.

\section{ACKNOWLEDGEMENTS}

Open access funding provided by Montanuniversitaet Leoben. The financial support by the Austrian Federal Ministry of Digital and Economic Affairs and the National Foundation for Research, Technology and Development is gratefully acknowledged.

\section{OPEN ACCESS}

This article is distributed under the terms of the Creative Commons Attribution 4.0 International License (http://creativecommons.org/licenses/by/4.0/), which permits unrestricted use, distribution, and reproduction in any medium, provided you give appropriate credit to the original author(s) and the source, provide a link to the Creative Commons license, and indicate if changes were made.

\section{REFERENCES}

1. S. Luidold, Herausforderungen beim Recycling wolframhaltiger Schrotte, Berliner Recyclingkonferenz, pp. $155-164$.

2. B.V. Lenntech, (Cobalt), https://www.lenntech.de/pse/eleme nte/co.htm. Accessed 07 Oct 2019.

3. G.P. Vassilev and M. Jiang, Thermodynamic Optimization of the Co-Zn-System. J. Phase Equilibria Diffusion 25, 259268 (2004).

4. T. Ebner, Konzepte zur Optimierung des Hartmetallrecyclings, Dissertation, Montanuniversität, Leoben, (2016).

5. T. Angerer, S. Luidold and H. Antrekowitsch, Technologien zum Recycling von Hartmetallschrotten (Teil 1), (World of Metallurgy-Erzmetall, 2011), pp. 6-15.

6. W. Schedler, Hartmetall für den Praktiker (Düsseldorf: VDIVerlag des Vereins Deutscher Ingenieure, 1988).

7. T. Seiler, Ultrafeinkörnige Hartmetalle mit Co-Binder und alternativen Bindersystemen-Korrelation von Mikrostruktur und mechanischem Verhalten unter monoton ansteigender und 
zyklisch wechselnder Beanspruchung, Dissertation, Universität Erlangen-Nürnberg, Erlangen-Nürnberg, (2002).

8. J. Garcia, Hartmetall für Schneidplatten und Kurbelwellenfräsern, (2005).

9. R. Kieffer, P. Schwarzkopf, and F. Benesovsky, Hartstoffe und Hartmetalle (Berlin: Springer, 1953).

10. Z. Fang, M. Koopman and H. Wang, Cemented tungsten carbide hard metal-an introduction, in Comprehensive Hard
Materials, University of Utah, Salt Lake City, (2014), pp. 123-137.

Publisher's Note Springer Nature remains neutral with regard to jurisdictional claims in published maps and institutional affiliations. 